Gut, 1982, 23, 194-197

\title{
Enzymatic characteristics of tubular adenomas and carcinomas of the large intestine
}

\author{
M H VATN*, S TJORA, P H ARVA, A SERCK-HANSSEN, AND J H STROMME \\ From The Laboratory of Gastroenterology, Department 9 Central Laboratory, and Department of Pathology, \\ Ulleval University Hospital, Oslo, Norway
}

SUMMARY Enzyme activities in homogenates of the large intestine were measured in biopsies from 11 tubular adenomas and six carcinomas and from the corresponding normal mucosa of each individual. A similar and significant increase was found in the total activities of glucose-6-phosphate dehydrogenase (G 6 PD), pyruvate kinase, and lactate dehydrogenase in adenomas and carcinomas as compared with the levels of normal mucosa. The lactate dehydrogenase isoenzyme patterns showed also a marked and similar change in the adenomas and carcinomas with a significant increase of lactate dehydrogenase M-monomers. Most of the adenomas showed slight to moderate dysplasia. The results indicate that the measurement of total G 6 PD, pyruvate kinase and lactate dehydrogenase activities for screening purposes has no predictive value in separating nonpremalignant from premalignant adenomas. Moreover, it seems that the enzymatic characteristics of malignancy are present even in tubular adenomas. This is in agreement with the theory of a polypcancer sequence.

Tubular adenomas are believed to be precursors of the majority of carcinomas of the large intestine..$^{1-3}$ Previous studies have demonstrated a high prevalence of tubular adenomas compared with carcinomas in the European as well as in the American population above 50 years of age..$^{4-6}$ This suggests that only a few adenomas become malignant, and that the prognosis of adenomas may vary, despite similar histological appearance.

It is well established that the patterns of enzyme activities in cancer are different from those of normal tissue. This has been partly attributed to an altered gene expression. Enzymatic changes have been shown in transplantable cancers in laboratory animals, ${ }^{78}$ as well as in various tissues of humans. ${ }^{9-12}$ Where the colon is concerned, the total activities of G 6 PD, lactate dehydrogenase and pyruvate kinase have been shown to be higher in cancer than in normal mucosa..$^{9} 13$ Mate et al. ${ }^{15}$ found an increase in the relative amounts of lactate dehydrogenase M-monomers, and Langvad $^{16}$ found a significant rise in the lactate dehydrogenase $_{4} /$ lactate dehydrogenase $_{2}$ ratio of colonic cancer.

*Address for correspondence: Morten H Vatn, Med A, Rikshospitalet, Oslo 1, Norway.

Received for publication 14 August 1981
As far as we know enzyme activities have not been measured in homogenates from tubular adenomas of the colon. The present study was carried out in order to see whether the above-mentioned difference in prognosis of tubular adenomas might be apparent from a shift in their enzyme patterns.

\section{Methods}

Polyps were removed by sling resection, and biopsies from carcinomas and, for comparison, from normal mucosa were taken during routine colonoscopy. Biopsies from the normal mucosa were always taken more than $5 \mathrm{~cm}$ from the tumour. The specimens were quenched. When kept on ice, the polyps were cut, and two pieces from the parietal part of the polyp and samples from the other materials were stored within two hours at $-70^{\circ} \mathrm{C}$. The rest of the polyp, including the stalk, and biopsies from normal mucosa and cancer were kept in $4 \%$ formol fixation before histological examination. Tubular adenomas were graded as slight, moderate, and severe dysplasia.

\section{ENZYME EXÄMINATION}

Tumour and the corresponding normal mucosa were analysed at the same time. All preparations were done on ice. Each biopsy was homogenised by four strokes in a Potter Elvehjem homogeniser. The homogenates 
were centrifuged at $17500 \mathrm{~g} / \mathrm{min}$ at $4^{\circ} \mathrm{C}$. The activities of $\mathrm{G} 6 \mathrm{PD}$, pyruvate kinase and lactate dehydrogenase in the supernatants were assayed at $37^{\circ} \mathrm{C}$ on a 8600 LKB reaction rate analyser. All measurements were done in duplicate. G 6 PD was measured according to the method of Kornberg and Horecker ${ }^{17}$ lactate dehydrogenase according to the Scandinavian recommendations, ${ }^{18}$ and pyruvate kinase according to Beisenherz et al..$^{19}$

The lactate dehydrogenase isoenzyme pattern of the supernatants (aliquots frozen to $-70^{\circ} \mathrm{C}$ immediately after preparation) was assayed after thawing on the next day in duplicates on agarose (Litex) gel electrophoresis in $0.05 \mathrm{~mol} / \mathrm{l}$ veronal buffer at $\mathrm{pH} \mathrm{8.6.} \mathrm{The}$ plates were stained according to the procedure of Rosalki, ${ }^{20}$ and scanned on a Vitratron TDL-100 scanner. The relative amount of $\mathrm{M}$-monomers in the supernatant was calculated from the scans.

The protein content in the supernatant was measured by the method of Lovry et al. ${ }^{21}$ Only aliquots containing more than $0.15 \mathrm{~g} / 1$ of protein in the supernatant were included in the material. The average protein concentration in the supernatants of the polyp group was 0.79 $\pm 0.30 \mathrm{~g} / 1$, in the corresponding normal mucosa group $0.45 \pm 0.28 \mathrm{~g} / \mathrm{l}$, in the supernatants of the carcinoma group $0.97 \pm 0.25 \mathrm{~g} / 1$, and in the corresponding normal mucosa group $0.78 \pm 0.26 \mathrm{~g} / \mathrm{l}$.

\section{CALCULATIONS}

Wilcoxon's test for paired comparisons was used to determine the difference in enzymatic activities of normal and neoplastic lesions. The statistical analysis were based on mean activity values \pm standard deviations (SD). P values less than 0.05 were regarded as significant.

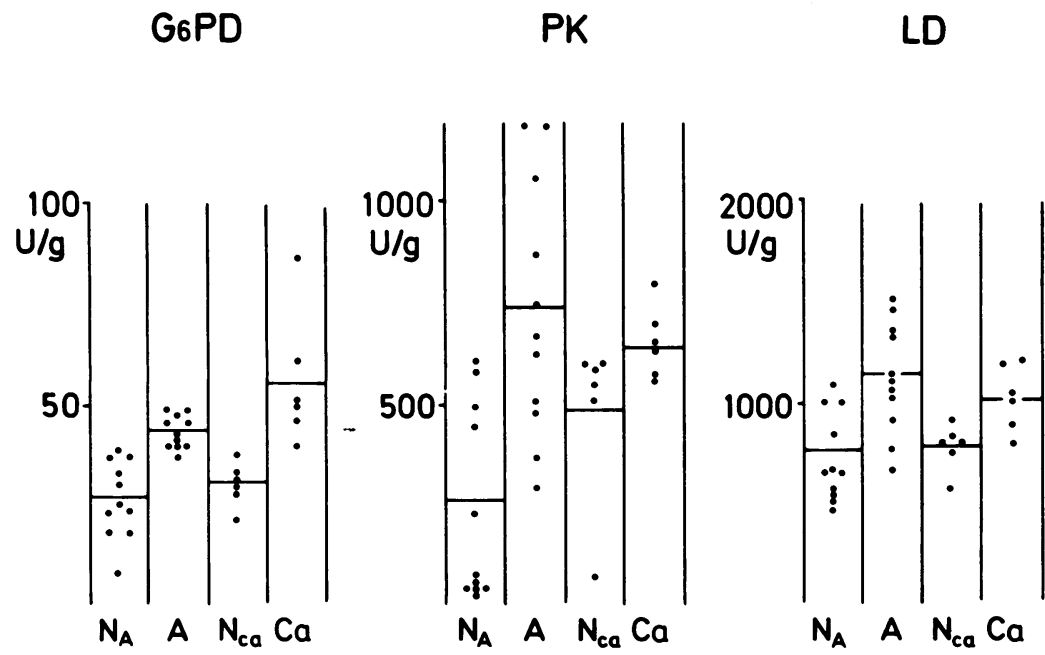

Results

Histologically, eight polyps showed slight to moderate dysplasia. One polyp showed areas of severe dysplasia, and two polyps showed general severe dysplasia.

\section{G 6 PD, PyruVAte Kinase, AND lactate} DEHYDROGENASE

G 6 PD, pyruvate kinase and lactate dehydrogenase activities in the supernatant of adenomas as well as of carcinomas were found on the average to be increased compared with the activities of normal mucosa (Fig. 1).

In adenomas the G 6 PD increased in all individuals with an average of about $65 \%$ (mean activity from 26.6 \pm 10 to $43.5 \pm 4 \mathrm{U} / \mathrm{g}, \mathrm{P}<0.002$ ), the pyruvate kinase increased in 10 of 11 individuals with an average of about $185 \%$ (from $262 \pm 237$ to $752 \pm 345 \mathrm{U} / \mathrm{g}$, $P<0.004)$, and the lactate dehydrogeñase increased in nine of 11 individuals with an average of about $50 \%$ (from $779 \pm 222$ to $1171 \pm 306 \mathrm{U} / \mathrm{g}, \mathrm{P}<0.005$ ). All enzymes showed overlapping of the total activities between normal mucosa and adenomas (Fig. 1).

In carcinomas the $G 6$ PD activity increased in all of six individuals with an average of about $85 \%$ (from 30.5 \pm 6 to $56.2 \pm 17 \mathrm{U} / \mathrm{g}, \mathrm{P}<0.02$ ). The pyruvate kinase activity increased in five of six individuals with an average of about $35 \%$ (from $492 \pm 211$ to $659 \pm 87 \mathrm{U} / \mathrm{g}$, $P<0.04)$, and the lactate dehydrogenase increased in all individuals with an average of about $35 \%$ (from 799 \pm 116 to $1077 \pm 165 \mathrm{U} / \mathrm{g}, \mathrm{P}<0.02)$. Overlapping was also found in this group (Fig. 1).

\section{LACTATE DEHYDROGENASE ISOENZYMES}

Lactate dehydrogenase isoenzymes in the supernatant of adenomas and carcinomas also showed parallel 


\section{LDISOENZYMES $\square$ NORMAL MUCOSA $\square$ NORMAL MUCOSA ZD ADENOMAS

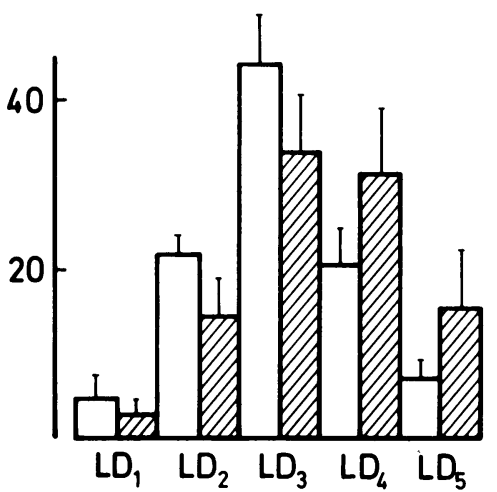

Table Activity of lactate dehydrogenase M-monomeres in supernatant of tubular adenomas $(A)$ and of carcinomas $(C)$ compared with normal mucosa $(N)$ (expressed in percentage of total lactate dehydrogenase activity)

\begin{tabular}{|c|c|c|c|}
\hline \multicolumn{2}{|c|}{ Adenomas } & \multicolumn{2}{|c|}{ Carcinomas } \\
\hline$N$ & $A$ & $N$ & $C$ \\
\hline $\begin{array}{l}52 \\
48 \\
54 \\
51 \\
49 \\
55 \\
52 \\
53 \\
43\end{array}$ & $\begin{array}{l}52 \\
59 \\
61 \\
63 \\
62 \\
56 \\
71 \\
71 \\
59\end{array}$ & $\begin{array}{l}50 \\
48 \\
46 \\
49 \\
45 \\
55\end{array}$ & $\begin{array}{l}60 \\
57 \\
62 \\
61 \\
60 \\
55\end{array}$ \\
\hline $50 \cdot 8 \pm 4$ & $61 \cdot 6 \pm 6$ & $48 \cdot 7 \pm 3$ & $59 \cdot 2 \pm 3$ \\
\hline \multicolumn{2}{|c|}{$\mathrm{P}<0.002$} & \multicolumn{2}{|c|}{$\mathrm{P}<0.02$} \\
\hline
\end{tabular}

changes in their activities (Fig. 2). Compared with that in the corresponding normal mucosa, the M-monomer activity in adenomas increased in eight of nine individuals and in five of six individuals of the carcinoma group (Table). The activity remained unchanged in one specimen of each group. The increased M-monomer activity caused an increase in the lactate dehydrogenase $_{4} /$ lactate dehydrogenase $e_{2}$ ratio from $0.85 \pm 0.2$ in normal mucosa to $2.8 \pm 1.4$ in adenomas $(P<0.002)$, and from $0.72 \pm 0.3$ in normal mucosa to 1.76 in cancers $(\mathrm{P}<0.02)$.

\section{Discussion}

By the comparatively crude biopsy and preparation technique used in the present study, a considerably heterogenity must be expected with regard to the tissue and cell composition that the final preparations reflect. This holds true from patient to patient, and even from sample to sample of basically the same material. Cau- tion must therefore be exercised when interpreting the results. From a diagnostic point of view, however, we consider the heterogenity of less importance, and the technique was chosen to be simple enough to carry it out on a routine basis. With this technique, we have found in polyps a significant increase of $G 6 \mathrm{PD}$, pyruvate kinase, and total lactate dehydrogenase and lactate dehydrogenase $\mathbf{M}$-monomers compared with that in normal mucosa. Similar changes have also been shown in the cancer group, the latter being in accordance with previous studies. ${ }^{912}$ 14-16 $^{16}$ Thus, examination of enzyme activities does not seem to separate tubular adenomas from cancer.

Studies on cell cycle parameters in the human colon, ${ }^{24}$ and histochemical analysis of hydrolytic, proteolytic, and respiratory activities of cells, ${ }^{25}$ have not given support to the concept of tubular adenomas as precancerous lesions. The present study, for the first time, shows corresponding enzymatic changes in homogenates from tubular adenomas and carcinomas. The results may indicate that changes in the glycolysis or pentose metabolism may be essential mechanisms for the development of cancer.

The somewhat higher mean activity of M-monomers corresponding to higher lactate dehydrogenase ${ }_{4} /$ lactate dehydrogenase ${ }_{2}$ ratio found in preparations of adenomas compared with carcinomas is due to the high M-monomer activity of the two adenomas with general severe dysplasia ( $71 \%$ in both cases, Table). The possibility of a transient increase of $\mathrm{M}$-monomers during malignant transformation needs to be further investigated.

Although we have demonstrated that tubular adenomas and carcinomas have common enzymatic patterns, additional studies are needed to clarify the role of the present parameters in the development of carcinoma of the colon. 


\section{References}

1 Morsion B. The polyp-cancer sequence in the large bowel. Proc R Soc Med 1974; 67:451-7.

2 Lane N, Fenoglio CM. The adenoma-carcinoma sequence in the stomach and colon. 1:Observations on the adenoma as precursor to ordinary large bowel carcinoma. Gastrointest Radiol 1976; 1:111-19.

3 Enterline HT. Polyps and cancer of the large bowel. Curr Top Pathol 1976; 63:95-141.

4 Correa P, Strong JP, Reif A, et al. The epidemiology of colorectal polyps. Prevalence in New Orleans and international comparisons. Cancer 1977; 39:2258-64.

5 Eide TJ, Stalsberg H. Polyps of the large intestine in Northern Norway. Cancer 1978; 42:2839-48.

6 Vatn MH, Stalsberg H. The prevalence of polyps of the large intestine in Oslo. An autopsy study. Cancer 1981; in press.

7 Weber G. Enzymology of cancer cells. N Engl J Med 1977; 296:486-93, 541-51.

8 Weinhouse S, Shatton JB, Morris HP. Isoenzyme composition, gene regulation and metabolism of experimental hepatomas. In: Schulz E, Ahmed J, eds. Winter Symposia Cancer enzymology. vol. 12 New York: Academic Press, 1979.

9 Bär U, Schmidt E, Schmidt FW. Enzym-Muster und Isoenzyme menschlicher Tumoren. Klin Wschr 1963; 41:977-88.

10 Latner AL, Turner DM, Way SA. Enzyme and isoenzyme studies in preinvasive carcinoma of the cervix. Lancet 1966; 2:814-16.

11 Langvad E. Lactate dehydrogenase isoenzyme patterns in Bronchogenic carcinoma. Europ J Cancer 1968; 4:107-15.

12 McCormick D, Allen IV. The value of LDH isoenzymes in the rapid diagnosis of brain tumors. Neuropathol Appl Neurobiol 1976; 2:269-78.

13 Shonk CE, Arinson RN, Koven BJ, et al. Enzyme patterns in human tissues III. Glycolytic enzymes in normal and malignant tissues of the colon and rectum. Cancer Res 1965; 25:206-13.
14 Briand P, Fischerman K. The activity of phosphofructokinase and lactate dehydrogenase in cancer of the colon and rectum, and the effect of iodine on the normal mucosa. Acta Chir Scand 1973; 139:666-70.

15 Maté J, Pajares JM, Cano R, et al. LDH isoenzyme electrophoretic pattern differences between colloid and other adenocarcinomas of the colon. Am J Dig Dis 1977; 22:874-6.

16 Langvad E, Lactate dehydrogenase isoenzyme patterns in the tumor-bearing colon. Int J Cancer 1968; 3:17-29.

17 Kornberg A, Horecker BL. Glucose-6-phosphate dehydrogenase. In: Methods in enzymology I, New York: 1955:Academic Press, 323-27.

18 The Committee on Enzymes of the Scandinavian Society for Clinical Chemistry and Clinical Physiology. Recommended methods for the determination of four enzymes in blood. Scand J Clin Lab Invest 1974; 33:291-306.

19 Beisenherz G, Boltze HJ, Bücher TP, et al. Diphosphofructose-Aldolase, PhosphoglyceraldehydDehydrogenase, Milchsäure-Dehydrogenase, Glycerophosphat-Dehydrogenase und Pyruvat-Kinase aus Kaninchenmuskulatur in einem Arbeitsgang. $Z$ Naturforsch 1953; 8b:555-77.

20 Rosalki SR. Standardization of isoenzyme assays with special reference to lactate dehydrogenase isoenzyme electrophoresis. Clin Biochem 1974; 7:29-40.

21 Lovry $\mathrm{OH}$, Rosebrough NJ, Farr AL, et al. Protein measurement with the folin phenol reagent. $J$ Biol Chem $1951 ; 193: 265-75$.

22 Tayler R, Cumberland VH, Piper DW. Lactate Dehydrogenase Isoenzyme pattern in uninvolved mucosa of patients with colorectal carcinoma. Gut 1977; 18:45-7.

23 Langvad E, Jemec B. Prediction of local recurrence in colorectal carcinoma: An LDH isoenzymatic assay. $\mathrm{Br} J$ Cancer 1975; 31:661-4.

24 Bleiberg H, Salhadin A, Galand P. Cell cycle parameters in human colon. Comparison between primary and recurrent adenocarcinomas, benign polyps, and adjacent unaffected mucosa. Cancer 1977; 39:1 190-4.

25 Nachlas MN. Histochemical observations on the polypcarcinoma sequence. Surg Gynecol Obstet 1961; 112: $534-42$. 